\title{
Novel mutations in the KCNQ2 gene link epilepsy to a dysfunction of the KCNQ2-calmodulin interaction
}

\author{
M C Richards, S E Heron, H E Spendlove, I E Scheffer, B Grinton, S F Berkovic, J C Mulley, A Davy
}

J Med Genet 2004;41:e35 (http://www.jmedgenet.com/cgi/content/full/41/3/e35). doi: 10.1136/jmg.2003.013938

M utations in the voltage gated potassium channels KCNQ2 (OMIM 602235) and KCNQ3 (OMIM 602232 ) are associated with an autosomal dominant idiopathic epilepsy syndrome of newborns, benign familial neonatal seizures (BFNS) (OMIM 121200). BFNS is characterised by unprovoked partial seizures typically beginning when the infant is around three days old. BFNS associated genes were mapped to human chromosomes $20 \mathrm{q} 13.3^{1}$ and $8 \mathrm{q} 24,{ }^{2}$ which led to the identification by positional cloning of KCNQ2 as the chromosome 20 gene. ${ }^{34}$ KCNQ3 was subsequently identified as the 8q24 BFNS gene, based on genomic location and homology with KCNQ2.

The potassium channels of the KCNQ gene family consist of four subunits, each with a 6 transmembrane topological organisation. KCNQ subunits, comprising KCNQ1-5, have an intracellular amino terminus, a single pore loop (P-loop) that forms the selectivity filter of the channel, ${ }^{6}$ a positively charged, voltage sensing fourth transmembrane domain (S4), and a large intracellular carboxy terminus (C-terminus). All five known KCNQ proteins can form homomeric channels, but the association of specific subunits to form heteromeric channels is restricted to certain combinations. ${ }^{6-10}$

KCNQ2 and KCNQ3 are mostly expressed in the central nervous system, ${ }^{3-5}$ where they form a heteromultimeric channel that mediates the neuronal muscarinic regulated current (M-current), also known as an M-channel (or M-type $\mathrm{K}^{+}$channel). The $\mathrm{M}$-current is a slowly activating, noninactivating potassium conductance known to regulate neuronal excitability by determining the firing properties of neurones and their responsiveness to synaptic input. ${ }^{11}$ Because it is active at voltages near the threshold for action potential initiation, the M-current has a major impact on neuronal excitability.

Since the KCNQ2/KCNQ3 ion channel plays a pivotal role in the regulation of neuronal excitability, it is not surprising that several mutations in the gene have been associated with epilepsy. The first $\mathrm{K}^{+}$channel mutations associated with epilepsy were reported in $1998^{3}{ }^{4}$ and more have subsequently been reported in both KCNQ2 and KCNQ3.

Whilst it is generally hypothesised that mutations in either KCNQ2 or KCNQ3 may result in a mild reduction of the Mcurrent and subsequent dysfunction of the neuronal response to synaptic input, for the most part no significant dominant negative effects or alterations in channel gating or ion selectivity have been observed. ${ }^{3}{ }^{12} 13$ In one BFNS family, a mutation in the voltage-sensing S4 domain of KCNQ2 was shown to have a dominant negative effect on channel activation; however this was associated with the occurrence of myokymia in patients. ${ }^{14}$

KCNQ2 C-terminal mutations account for over half of all known mutations associated with BFNS and to date there have been no functional studies elucidating the pathogenic effects of such mutations. Recently, the interaction between the C-terminal region of KCNQ2 and the ubiquitous calcium binding protein calmodulin ( $\mathrm{CaM})$ has been reported, ${ }^{15-17}$

\section{Key points}

- We set out to ascertain KCNQ2 mutations in 10 families with benign familial neonatal seizures (BFNS), and to determine if any mutations from the $\mathrm{C}$-terminal region affected the interaction between KCNQ2 and the ubiquitous calcium sensing protein, calmodulin (CaM).

- Eight novel mutations were found: two missense start codon mutations and a frameshift mutation in the $\mathrm{N}$ terminal region and a truncation, two putative splice site mutations and two missense mutations in the Cterminal region.

- Using a yeast two hybrid assay, we determined that the KCNQ2 C-terminal missense mutations R353G and L619R both affect normal CaM binding. The R353G mutation lies within one of the two putative CaM binding regions and the L619R lies within close proximity of the other.

- On the basis of our data we postulate that dysfunction of CaM binding may be one of the pathogenic mechanisms associated with benign familial neonatal seizures.

suggesting a possible pathogenic mechanism of action for Cterminal KCNQ2 mutations.

Here, we report the association of eight novel KCNQ2 mutations in families with benign familial neonatal seizures. Specifically, we show that two missense mutations affect the binding affinity of CaM and we discuss the involvement of an aberrant KCNQ2-CaM interaction in epileptogenesis.

\section{MATERIALS AND METHODS}

\section{Clinical data}

Detailed clinical histories and pedigrees were obtained from families where two or more individuals had neonatal seizures, without a known extraneous cause. Venous blood was sampled for DNA extraction. The study was approved by the Austin and Repatriation Medical Centre Committee on Human Ethics.

Abbreviations: BFNS, benign familial neonatal seizures; $\mathrm{CaM}$, calmodulin; C-terminus, carboxy terminus; KCNQ2, Homo sapiens potassium voltage gated channel, KQT-like subfamily, member 2; KCNQ3, Homo sapiens potassium voltage gated channel, KQT-like subfamily, member 3; P-loop, pore loop; $M$-current, neuronal muscarinic regulated current; S1-6, first to sixth transmembrane domains 


\section{Mutation screening}

KCNQ2 was screened by single strand conformation polymorphism analysis or sequencing as described elsewhere. ${ }^{18}$ Primer sequences for these and all other primers from the study are available from the authors upon request.

\section{Generation of yeast two-hybrid screen constructs}

A yeast two hybrid screen was carried out using the ProQuest $^{\mathrm{TM}}$ Two-Hybrid System with Gateway ${ }^{\mathrm{TM}}$ Technology (Invitrogen ${ }^{\mathrm{TM}}$, Australia) according to the manufacturer's directions. A KCNQ2 C-terminal entry clone was generated using the pENTR Directional TOPO ${ }^{\circledR}$ Cloning Kit (Invitrogen $^{\text {TM }}$, Australia). Primers were designed to amplify the intracellular C-terminal region of KCNQ2 based on the sequence of human KCNQ2 (Genbank accession number NM_172107). The 1611 bp cloned fragment included exon 10a (found in all our amplified clones), corresponding to aa $373-382 .^{3}{ }^{19}$ The extra $30 \mathrm{bp}$ (10 aa) were included in our numbering. Following sequence verification, the KCNQ2 cDNA fragment was then subcloned into $\mathrm{pDEST}^{\mathrm{TM}} 32$, the DNA Binding domain (DB) Gateway ${ }^{\mathrm{TM}}$ Destination Vector (Invitrogen $^{\mathrm{TM}}$, Australia).

\section{KCNQ2 C-terminal bait mutagenesis}

Primers were designed to incorporate the c.1057C $>\mathrm{G}$ (R353G) and c. 1856T $>$ G (L619R) changes into the

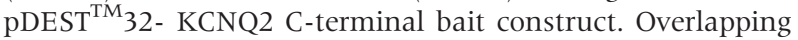
PCR products were amplified, gel extracted and purified before a second round of PCR using the initial KCNQ2 F and $\mathrm{R}$ primers. These products were also gel extracted before cloning into the pDEST ${ }^{\mathrm{TM}_{32}}$ bait vector using the $\mathrm{TOPO}^{\circledR}$ system. Mutant baits were sequence verified.

\section{Yeast two-hybrid assay}

The DBLeu (empty bait vector), DB-KCNQ2 wild-type (DBQ2C wt) and mutant (R353G, L619R) C-term baits were transformed into the yeast strain Mav203 and plated onto minimal selective media lacking leucine. A duplicate was carried out, in which the empty Activation Domain (pAD) prey vector was cotransformed with the baits and plated onto minimal selective media lacking leucine (-Leu) and tryptophan (-Trp). Yeast control strains (Invitrogen ${ }^{\mathrm{TM}}$ ) were included on all plates. Control 1 , used as a negative control, contains empty plasmids pPC97 and pPC86. Control 2 has pPC97-RB and pPC86-E2F1, which express a relatively weak interaction. Control 3 contains plasmids encoding the Drosophila DP (pPC97) and E2F (pPC86) domains that have a moderately strong interaction, and provide a control for plasmid shuffling. Control 4 contains pPC97-Fos and pPC86Jun which express a relatively strong interaction, and control 5 has a pCLl plasmid encoding full-length GAL4p and empty pPC86 and is used as a positive control. The constructs were tested for self-activation of the HIS3 and $\beta$-galactosidase reporter genes according to Invitrogen ${ }^{\mathrm{TM}}$ instructions. The interaction between each DB-Q2C mutant and CaM was then tested by yeast two-hybrid assay and compared to the interaction with DB-Q2 wt. Three different PCR amplified $\mathrm{CaM}$ clones were introduced by gap repair ${ }^{20}$ into the prey vector (pPC86) in the yeast strain expressing either DB-Q2C wt, DB-Q2C mutants, or the empty DBLeu vector, which was used as a negative control. CaM interaction with the DB-Q2C wt and mutants was then assessed by expression of the HIS3 and LacZ reporter genes.

\section{Yeast protein extraction}

Yeast cultures were prepared for protein extraction according to the Clontech protocol. Protein extracts were prepared by the Urea and sodium dodecyl sulphate method described elsewhere. $^{21}$

\section{Western blotting}

The NuPage ${ }^{\circledR}$ Novex 4-12\% Bis-Tris Pre-cast gel system (Invitrogen $^{\mathrm{TM}}$, Australia) was used to analyse the yeast protein extracts. Gels were run according to the manufacturer's instructions. A $42 \mathrm{kDa}$ Gal4 (DBD-1-147) positive control (Santa Cruz Biotechnology, Inc., Santa Cruz, California) and MagicMark ${ }^{\mathrm{TM}}$ Western Protein Standard (Invitrogen $^{\mathrm{TM}}$, Australia) were run on the gel for comparison. A 1:1000 dilution of the mouse monoclonal Gal4 (DBD) antibody (RK5Cl, Santa Cruz Biotechnology, Inc., Santa Cruz, CA) was used as the primary antibody, followed by a 1:5000 dilution of the horseradish peroxidase conjugated sheep antimouse immunoglobulin secondary antibody (Silenus Labs, Pty. Ltd., Australia). The membrane was visualised with SuperSignal ${ }^{\circledR}$ West Dura Extended Duration Substrate (Pierce Biotechnology, Inc., Rockford, IL).

\section{Assay for $\beta$-galactosidase activity in liquid culture using chlorophenol red- $\beta$-D-galactopyranoside}

The chlorophenol red- $\beta$-D-galactopyranoside assay was carried out according to the ProQuest ${ }^{\mathrm{TM}}$ Two-Hybrid System with Gateway ${ }^{\mathrm{TM}}$ Technology (Invitrogen ${ }^{\mathrm{TM}}$, Australia) instructions. The units of $\beta$-galactosidase in each sample were calculated, where 1 unit of $\beta$-galactosidase is defined as the amount that hydrolyses $1 \mu \mathrm{mol}$ of chlorophenol red- $\beta$-Dgalactopyranoside to chloramphenicol red and D-galactose in one minute:

$$
\beta \text {-galactosidase units }=\frac{1000 \times \mathrm{OD}_{574}}{\left(t \times V \times \mathrm{OD}_{600}\right)}
$$

where $V=$ volume of culture used in the assay $(\mathrm{ml})$; $\mathrm{OD}_{574}=$ optical density at $574 \mathrm{~nm}$, which is equal to the absorbance by chloramphenicol red (and light scattering by cell debris); $\mathrm{OD}_{600}=$ optical density at $600 \mathrm{~nm}$, which is equal to the cell density at the start of the assay. Data were analysed with Microsoft ${ }^{\circledR}$ Excel 2000 and for statistical evaluation, a two-tailed, unpaired Student's $t$ test was applied.

\section{RESULTS AND DISCUSSION}

Novel KCNQ2 mutations were found in eight out of ten BFNS families in our study. All of the mutations were found on one allele only (-that is, patients were heterozygous) and were shown to segregate within the families. None of the mutations were detected in at least 50 unaffected control samples. The novel mutations that we found comprised two mutations of the start codon (MIV, MIT), one frameshift (K69fsX119), one truncation (R430X), two putative splice site mutations (E49l and R570) and two missense mutations (R353G and L619R) (table 1 and fig l). The one base insertion at aa 69 creates a premature termination of the protein within the N-terminal domain of KCNQ2 and, along with the two mutations of the start codon, would act as an allelic knockout, likely to result in decreased KCNQ2 subunit expression and a concomitant reduction in neuronal $\mathrm{M}$ channels. The subsequent reduction in M-current in the brain is predicted to result in reduced inhibition of neuronal excitability, resulting in hyperexcitability as observed in benign familial neonatal seizures. The other five mutations are all located within the KCNQ2 C-terminal domain. All known mutations are shown in table 1 and fig 1 .

To date, most functional studies have been on mutations located within transmembrane domains. In particular mutations associated with BFNS and found in the voltage sensing S4 domain of KCNQ2 were shown to alter the gating properties of the M-channels, displaying slower opening and faster closing kinetics and a decreased voltage sensitivity 
Table 1 Summary of known BFNS mutations in the $\mathrm{KCNQ} 2$ potassium channel subunit. Numbering is based on the long form of KCNQ2 (including exon 10a)

\begin{tabular}{|c|c|c|}
\hline Variant & Amino Acid change & Location \\
\hline c. $1 \mathrm{~A} \rightarrow \mathrm{G}^{*}$ & MIV (no start) & $\mathrm{N}$-ter \\
\hline c. $2 \mathrm{~T} \rightarrow \mathrm{C}^{*}$ & MIT (no start) & $\mathrm{N}$-ter \\
\hline c. 204 ins $C^{*}$ & K69fs $\times 119$ & $\mathrm{~N}$-ter \\
\hline c. $585 \mathrm{ins}^{22 \dagger}$ & A196fsX262 & Loop $\|-\| I^{\dagger}$ \\
\hline c. $587 \mathrm{C} \rightarrow \mathrm{T}^{22}$ & A196V & S4 \\
\hline c. $590 \mathrm{~T} \rightarrow \mathrm{C}^{22}$ & L197P & S4 \\
\hline c. $619 \mathrm{C} \rightarrow \mathrm{T}^{14}$ & R207W & S4 \\
\hline c. $640 \mathrm{C} \rightarrow \mathrm{T}^{23}$ & $\mathrm{R} 214 \mathrm{~W}$ & S4 \\
\hline c. $740 C \rightarrow G^{24 \ddagger}$ & S247W & S5 \\
\hline c. $749 \mathrm{~T} \rightarrow \mathrm{G}^{22}$ & V250G & S5 \\
\hline c. 847 ins $\mathrm{TT}^{4}$ & $\mathrm{~K} 283 \mathrm{fs}_{\mathrm{s}} \times 319$ & P-loop \\
\hline c. $851 \mathrm{~A} \rightarrow \mathrm{G}^{4}$ & Y284C & P-loop \\
\hline c. $926 \mathrm{G} \rightarrow \mathrm{A}^{4}$ & A306T & S6 \\
\hline c. $1016 \mathrm{~T} \rightarrow \mathrm{G}^{22}$ & L339R & C-ter \\
\hline c. $1057 \mathrm{C} \rightarrow \mathrm{G}^{*}$ & R353G & C-ter \\
\hline c. $1221+2 \mathrm{~T} \rightarrow \mathrm{G}^{25}$ & Splice donor site (K407) & C-ter \\
\hline c. $1288 \mathrm{C} \rightarrow \mathrm{T}^{*}$ & Truncation (R430X) & C-ter \\
\hline Unknown $^{22}$ & $\mathrm{R} 458 \mathrm{X}^{\dagger}$ & C-ter \\
\hline c. $1471+1 G \rightarrow A^{*}$ & Splice donor site (E491) & C-ter \\
\hline c. 1510 del $13^{4}$ & $\mathrm{~S} 504 \mathrm{fs} \times 506$ & C-ter \\
\hline c. $1575+1 G \rightarrow A^{4}$ & Splice donor site (C526) & C-ter \\
\hline c. 1630 ins GCCCT $^{3}$ & Y544fs X549 & C-ter \\
\hline c. $1688 \mathrm{G} \rightarrow \mathrm{A}^{22}$ & $\mathrm{R} 563 \mathrm{Q}$ & C-ter \\
\hline c. $1710 \mathrm{~A} \rightarrow \mathrm{T}^{*}$ & Exonic splice site (R570) & C-ter \\
\hline c. $1856 \mathrm{~T} \rightarrow \mathrm{G}^{*}$ & L619R & C-ter \\
\hline c. 1876 delT ${ }^{26}$ & Y626fsX910 & C-ter \\
\hline c. 2073 delT ${ }^{27}$ & P691 fsX911 & C-ter \\
\hline c. $2543 \mathrm{del}^{12}$ & G848fsX91 1 & C-ter \\
\hline
\end{tabular}

*Our data; ${ }^{\dagger}$ Numbering according to authors; ${ }^{\text {}}$ Phenotype not compatible with typical benign familial neonatal seizures

with no concomitant changes in maximal current or membrane expression. ${ }^{14} 2829$

Effects of mutations in the KCNQ2 C-terminal domain are less well understood, although the cytoplasmic C-terminal domain of KCNQ2 has been shown to be crucial for normal activity of the channel. ${ }^{12} 13193031$ The C-terminus accounts for $63 \%$ of the KCNQ2 protein and, in common with other KCNQ subunits, contains a conserved "A domain" 1332 thought to be involved in subunit interactions and another distal short conserved region that has been associated with subunit assembly, at least in KCNQ1.6 ${ }^{32}$ The subunit interaction domain, encompassing the A domain and the putative assembly domain, was recently found to determine the subunit specificity of KCNQ channel assembly, ${ }^{31}$ and consequently is essential for expression of functional homomeric or heteromeric channels. Heteromeric KCNQ2/KCNQ3 channels are expressed pre and postsynaptically, where they are likely to be associated with the cytoskeleton by means of scaffolding proteins. KCNQ2, because it is more resistant to detergent than KCNQ3, is hypothesised to contain a region, such as the subunit interaction domain, that is essential for such cytoskeletal interactions. ${ }^{33}$ Mutations within the KCNQ2 Cterminus clearly have the potential to disrupt subunit assembly and may explain why no dominant negative effects were observed in functional studies of a C-terminal truncating mutation. ${ }^{3}{ }^{6}$

Two C-terminal missense mutations (R353G and L619R) were found in families A and B respectively (fig 2) and were subject to detailed study, to assess their effect on CaM binding. The corresponding nucleotide changes (R353G: c. $1057 \mathrm{C} \rightarrow \mathrm{G}$, L619R: c.1856T $\rightarrow$ G) were introduced into a DB-Q2C construct by mutagenesis. The empty bait plasmid (DBLeu), DB-Q2C wt, DB-Q2C R353G mutant or DB-Q2C L619R mutant plasmids were transformed into Mav203 yeast strain as indicated in fig $3 \mathrm{~A}$ and protein expression was confirmed by Western blotting (data not shown). The interaction between each DB-Q2C mutant bait and CaM was then tested by yeast two hybrid assay and compared with the interaction with DB-Q2 wt and the control interactions. Fig 3B shows the growth of transformed yeast and controls on -Leu -Trp selection after $24 \mathrm{~h}$. Yeast can grow on -Leu if they contain the DB plasmid, and -Trp if they have the AD plasmid. Fig 3C shows growth of transformed yeast and controls on -Leu -Trp -His $+40 \mathrm{mM} 3 \mathrm{AT}$ selective plate after $48 \mathrm{~h}$. Only yeast cells where the expression of the His 3 reporter gene is activated by interaction between the bait and prey plasmids can grow on this selective plate. Figs 3D-F show a LacZ Filter assay for interaction between bait and prey plasmids after 2, 7, and $24 \mathrm{~h}$, respectively. A change in colour from cream to blue indicates activation of the $\beta$-galactosidase reporter gene by interaction of the bait and prey plasmids. The Q2C R353G mutant did not interact with CaM, as seen by no growth on HIS3 selective plate (fig 3C) and no blue readout in the $L a c Z$ filter assay (figs $3 \mathrm{D}-\mathrm{F}$ ). On the other hand, the DB-Q2C L619R mutant was shown still to interact with CaM, as seen by growth on an HIS3 selective plate (fig 3C) and the blue readout in the LacZ filter assay (figs 3DF). Interestingly, the DB-Q2C L619R mutant showed an even greater growth level on HIS3 selective plate than the DB-Q2C wt and also appeared to stain faster and more intensely blue in the LacZ filter assay, suggesting a stronger interaction between CaM and this mutant.

To quantify $\beta$-galactosidase activity more accurately, a second assay was carried out using the high sensitivity substrate chlorophenol red- $\beta$-D-galactopyranoside in liquid culture. The affinity of the DB-Q2C/AD-CaM interaction was measured in terms of units of $\beta$-galactosidase activity, with a zero value indicating no expression of the LacZ reporter gene, and hence no interaction. In the chlorophenol red- $\beta$-D-galactopyranoside assay, a value of 0.05 units $\beta$ galactosidase activity (fig 4) was significantly different from the empty bait vector replicate $(\mathrm{p}<0.01$, Student's $t$ test $)$, confirming the interaction of the DB-Q2C wt with CaM. As observed in the LacZ filter assay, the chlorophenol red- $\beta$-Dgalactopyranoside assay showed a significant difference in the interaction between the Q2C R353G mutant and CaM as compared to the wild-type replicate $(\mathrm{p}<0.01$, Student's $t$ test, fig 4).

These results suggest that the R353G mutation alters the structural conformation of the KCNQ2 C-terminal domain such that it is no longer able to bind to CaM. Indeed, the R353G missense mutation is within one of the CaM binding domains previously identified in KCNQ2 ${ }^{15}{ }^{16}$ (fig 1). By abolishing CaM binding, the R353G mutation could lead to an impairment of M-current in vivo, through decreased opening of the channel. This might be predicted to have a similar effect on neuronal excitability to truncation and frameshift BFNS mutations that disrupt the structure of the KCNQ2 protein.

This is supported by experiments where KCNQ2 mutants deficient in CaM binding co-expressed with KCNQ3 in Chinese hamster ovary cells did not give rise to detectable currents. ${ }^{15}$ The membrane targeting of the mutants was not altered, neither was the ability to co-assemble with KCNQ3, thus demonstrating that CaM binding is not necessary for membrane biogenesis of KCNQ2 or KCNQ3 channels. Furthermore, it has been suggested that some ion channel proteins have a binding sites for $\mathrm{Ca}^{2+}$-calmodulin. ${ }^{34}$ When this site is not occupied, the channel is in its inactivated (closed) conformation, but in response to an influx or internal release of $\mathrm{Ca}^{2+}$, calcified CaM binds to the channel, resulting in an activated (openable) form. Indeed, CaM was shown in two studies to be tethered constitutively to the Mchannel, suggesting that the C-terminal domain of KCNQ channels may fold in a manner that allows CaM to induce Mchannel opening. ${ }^{15} 16$ 


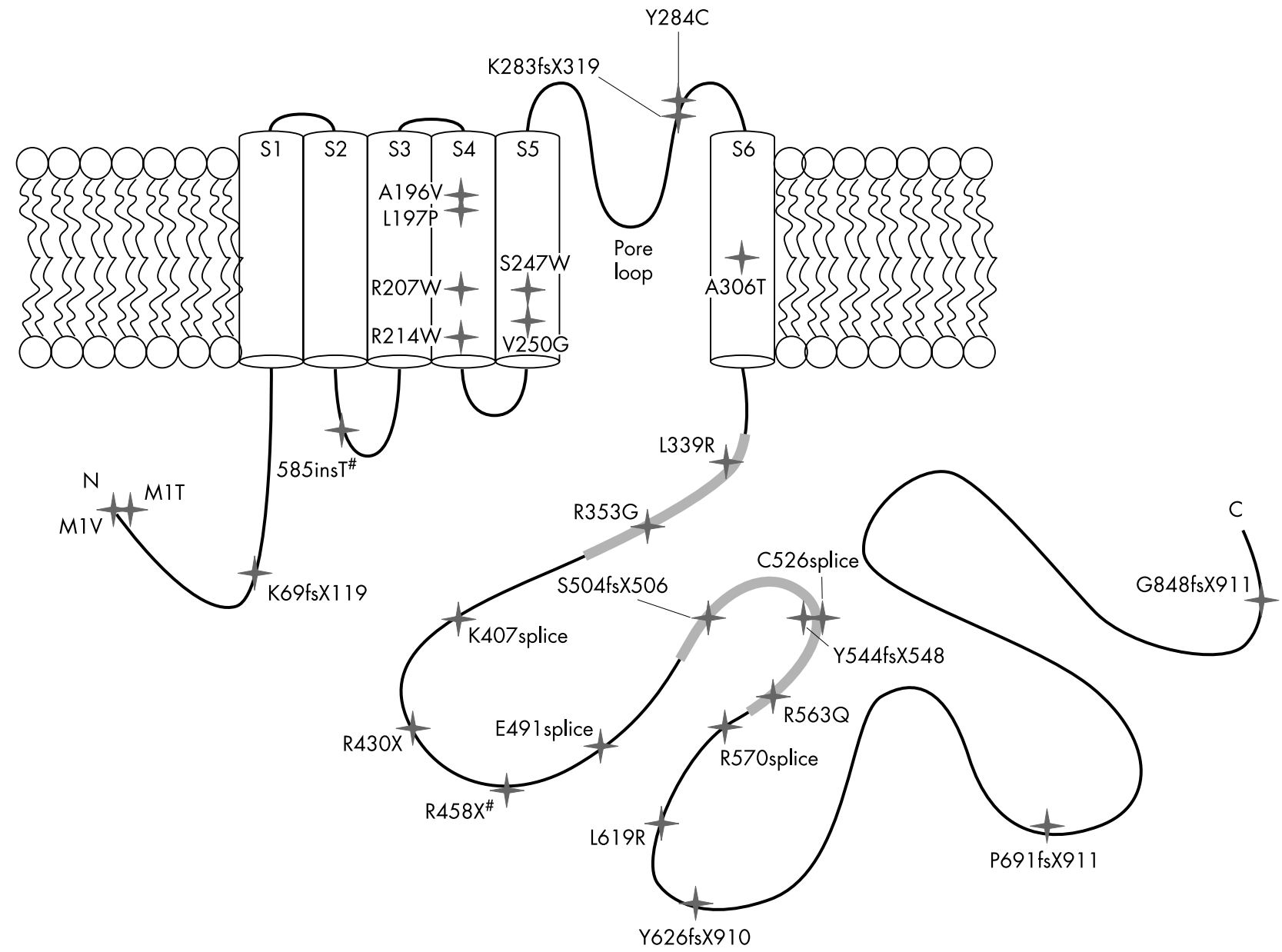

Figure 1 Model of the KCNQ2 channel protein showing the known mutations associated with BFNS, numbered according to the mutated residue. Numbering is based on the long form of KCNQ2 including exon 10a. " nomenclature according to the authors (see table 1). Grey regions of the Cterminal loop indicate $\mathrm{CaM}$ binding regions. ${ }^{15} 16$

Family A. KCNQ2 R353G
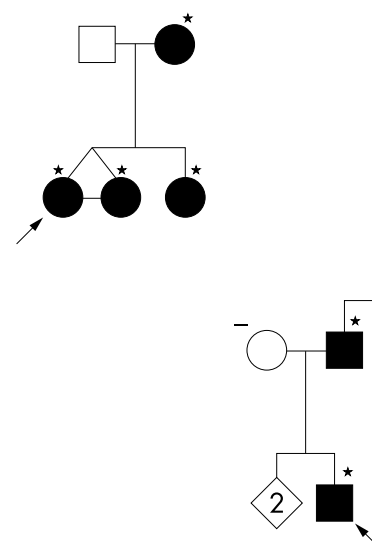

BFNS

Unclassified epilepsy

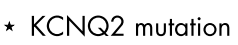

Miscarriage

Figure 2 Pedigrees of families with benign familial neonatal seizures. *, members carrying a KCNQ2 mutation that have been tested; -, members who were tested and are negative for the mutation.
In contrast, the chlorophenol red- $\beta$-D-galactopyranoside assay for the L619R Q2C mutant showed a significantly higher level of $\beta$-galactosidase activity ( 0.26 units) than the wild-type replicate $(\mathrm{p}<0.001$, Student's $t$ test, fig 4$)$. This finding indicates that the L619R mutation alters the conformation of the protein in a manner that increases CaM binding to the KCNQ2 C-terminal domain approximately fivefold.

More recent work by Gamper and Shapiro ${ }^{17}$ is consistent with a role for $\mathrm{CaM}$ in $\mathrm{Ca}^{2+}$ sensing rather than in channel assembly (as found by Wen and Levitan ${ }^{15}$ and Yus-Nájera et $\mathrm{al}^{16}$ ), or at least a dual role for CaM in KCNQ channel physiology. Their work suggests that bradykinin modulation of the M-current, at least in sympathetic neurones, uses CaM in concert with rises in calcium concentration $\left(\left[\mathrm{Ca}^{2+}\right]\right)$, over the physiological range of $<10-400 \mathrm{nM}$.

KCNQ2 and KCNQ3 channels are strongly modulated by several distinct signalling pathways in neurones that are mediated by second messengers, ${ }^{17}$ and these include $M_{1}$-type muscarinic receptors and activators of G-protein coupled receptors, such as bradykinin $\mathrm{B}_{2}{ }^{35}$ and purinergic $\mathrm{P}_{2} \mathrm{Y}_{2}{ }^{36}$ The signal provoked by the latter two receptors involves the phospholipase $\mathrm{C} /$ inositol triphosphate $\left(\mathrm{PLC} / \mathrm{IP}_{3}\right)$ pathway and release of $\mathrm{Ca}^{2+}$ from internal stores to produce rises in intracellular $\left[\mathrm{Ca}^{2+}\right] .^{35}$ 37-39

Gamper and Shapiro ${ }^{17}$ show that bradykinin induced rises in intracellular $\left[\mathrm{Ca}^{2+}\right]$ act on $\mathrm{M}$-channels via $\mathrm{Ca}^{2+}-\mathrm{CaM}$ to suppress the M-current. In the case of the KCNQ2 L619R 
A
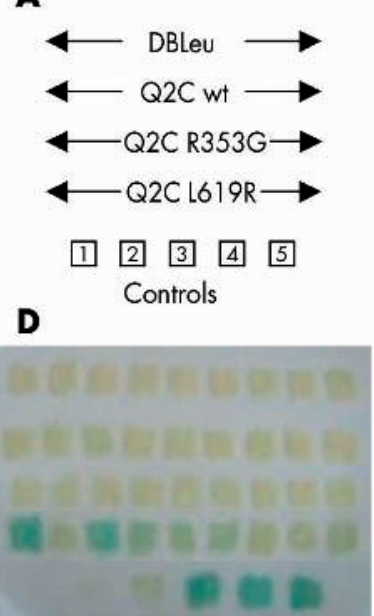

B

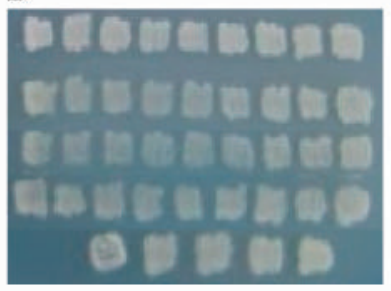

E

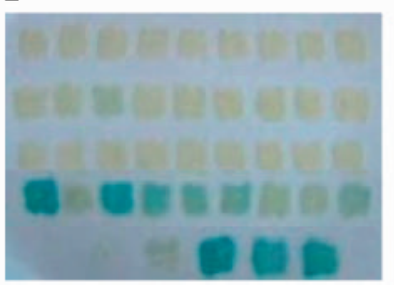

C
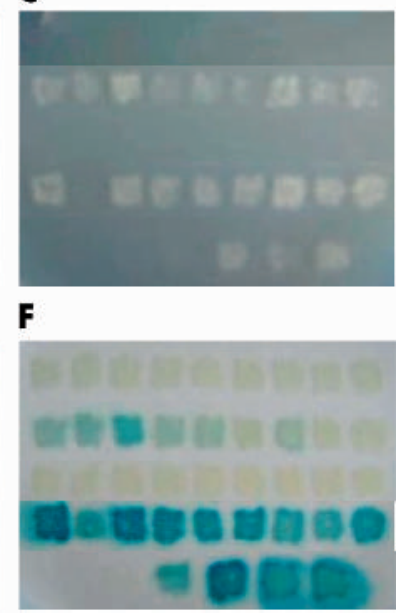

Figure 3 Digital images of yeast growth on selection plates. Yeast was transformed with the bait plasmids as indicated in (A) and the AD-CaM (prey) vector was introduced by gap repair. Yeast control strains (Invitrogen ${ }^{\top M}$, Australia) were included on all plates for comparison. Control 1 is a negative control, control 2 expresses a relatively weak interaction, control 3 expresses a moderately strong interaction, control 4 expresses a relatively strong interaction, and control 5 is used as a positive control for a strong interaction. (B) Growth of transformed yeast and controls on -Leu -Trp selection after $24 \mathrm{~h}$. (C) Growth of transformed yeast and controls on -Leu -Trp-His $+40 \mathrm{mM} 3 \mathrm{AT}$ after $48 \mathrm{~h}$. (D-F) LacZ Filter assay for interaction between bait and prey plasmids. Photos were taken after $2 \mathrm{~h}(\mathrm{D}), 7 \mathrm{~h}(\mathrm{E})$, and $24 \mathrm{~h}(\mathrm{~F})$.

mutation that results in increased binding of CaM to the Mchannel, it can be inferred that the effect of bradykinin modulation of M-channels would be amplified because of a likely increased sensitivity to $\left[\mathrm{Ca}^{2+}\right]$. Thus, in the case of the L619R mutant channel, in response to a rise in bradykinininduced intracellular $\left[\mathrm{Ca}^{2+}\right]$, the KCNQ2/KCNQ3 derived Mcurrent would be suppressed to a greater extent than for the wild-type channel. Suppression of the M-current would lead to decreased inhibition of neuronal excitability and could potentially be associated with BFNS pathogenicity.

\section{CONCLUSION}

Our results implicate CaM in the pathogenesis of epilepsy and specifically in the BFNS syndrome. Whilst further work will be required to elucidate fully the involvement of the KCNQ2-CaM interaction in neuronal excitability and its correlation with idiopathic epilepsy, these data suggest that dysfunction of this interaction leads to aberrant neuronal excitability in some BFNS patients.

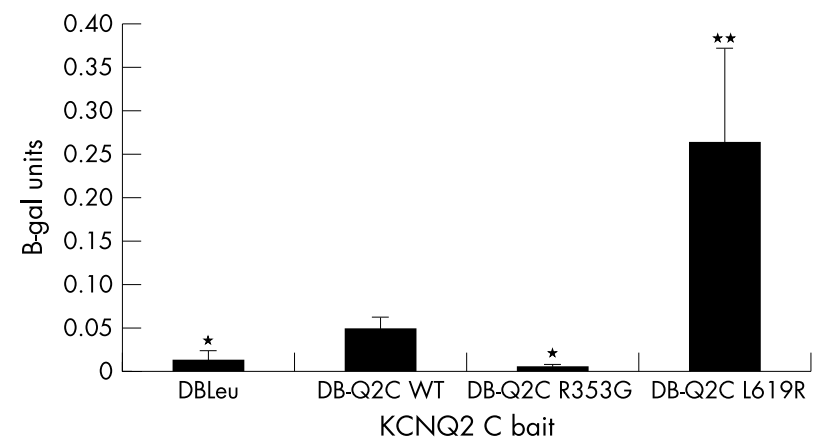

Figure 4 KCNQ2-CaM binding efficiency. Values from chlorophenol red- $\beta$-D-galactopyranoside assay for $\beta$-galactosidase (B-gal) activity as a measure of KCNQ2 C-terminus (Q2C) CaM binding efficiency. The area of each bar in the chart equates to the CaM binding efficiency of the bait (DB construct). DBLeu is the empty bait vector (negative control), $D B-Q 2 C$ wt bait contains the wild-type KCNQ2 C-terminal region, DBQ2C R353G bait carries the KCNQ2 R353G C-terminal mutation and the DB-Q2C L619R bait carries the L619R mutation. Statistical comparison to the DB-Q2C wt was carried out by two-tailed, unpaired Student's $t$ test, ${ }^{*} p<0.01,{ }^{* *} p<0.001$.

\section{ACKNOWLEDGEMENTS}

We thank the families for their participation and Allison J Hall for technical assistance. Family A was kindly referred by Dr Gregory Holmes (Children's Hospital, Boston) and family B by Dr Jeremy Freeman (Royal Children's Hospital, Melbourne).

\section{Authors' affiliations}

M C Richards, S E Heron, H E Spendlove, J C Mulley, Department of Laboratory Genetics, Women's and Children's Hospital, North Adelaide, South Australia, Australia

I E Scheffer, B Grinton, S F Berkovic, Epilepsy Research Institute and Department of Medicine (Neurology), University of Melbourne, Austin and Repatriation Medical Centre, Heidelberg, Victoria, Australia J C Mulley, Department of Molecular Biosciences, University of Adelaide, Adelaide, Australia

A Davy, Bionomics Ltd, 31 Dalgleish St., Thebarton, South Australia, Australia

The study was supported by the Australian National Health and Medical Research Council and Bionomics Ltd.

Bionomics Ltd funded part of the study.

Correspondence to: Dr A Davy, Bionomics Ltd, 31 Dalgleish St, Thebarton, SA, Australia, 5031; adavy@bionomics.com.au

Received 1 September 2003

Revised version received 21 October 2003

Accepted 28 October 2003

\section{REFERENCES}

1 Leppert M, Anderson VE, Quattlebaum T, Stauffer D, O'Connell P, Nakamura Y, Lalouel JM, White R. Benign familial neonatal convulsions linked to genetic markers on chromosome 20. Nature 1989;337:647-8.

2 Lewis TB, Leach RJ, Ward K, O'Connell P, Ryan SG. Genetic heterogeneity in benign familial neonatal convulsions: identification of a new locus on chromosome 8q. Am J Hum Genet 1993;53:670-5.

3 Biervert C, Schroeder BC, Kubisch C, Berkovic SF, Propping P, Jentsch TJ, Steinlein OK. A potassium channel mutation in neonatal human epilepsy. Science 1998:279:403-6.

4 Singh NA, Charlier C, Stauffer D, DuPont BR, Leach RJ, Melis R, Ronen GM, Bjerre I, Quattlebaum T, Murphy JV, McHarg ML, Gagnon D, Rosales TO, Peiffer A, Anderson VE, Leppert M. A novel potassium channel gene, KCNQ2, is mutated in an inherited epilepsy of newborns. Nat Genet 1998:18:25-9.

5 Charlier C, Singh NA, Ryan SG, Lewis TB, Reus BE, Leach RJ, Leppert M. A pore mutation in a novel KQT-like potassium channel gene in an idiopathic epilepsy family. Nat Genet 1998;18:53-5.

6 Jentsch TJ. Neuronal KCNQ potassium channels: physiology and role in disease. Nat Rev Neurosci 2000;1:21-9. 
7 Schroeder BC, Kubisch C, Stein V, Jentsch TJ. Moderate loss of function of cyclic-AMP-modulated KCNQ2/KCNQ3 K ${ }^{+}$channels causes epilepsy. Nature 1998;396:687-90.

8 Kubisch C, Schroeder BC, Friedrich T, Lütjohann B, El-Amraoui A, Marlin S, Petit $C$, Jentsch TJ. KCNQ4, a novel potassium channel expressed in sensory outer hair cells, is mutated in dominant deafness. Cell 1999;96:437-46.

9 Lerche C, Scherer CR, Seebohm G, Ders C, Wei AD, Busch AE, Steinmeyer K. Molecular cloning and functional expression of KCNQ5, a potassium channel subunit that may contribute to neuronal M-current diversity. J Biol Chem 2000;275:22395-400.

10 Schroeder BC, Hechenberger M, Weinreich F, Kubisch C, Jentsch TJ. KCNQ5, a novel potassium channel broadly expressed in brain, mediates $M$-type currents. J Biol Chem 2000;275:24089-95.

11 Wang H-S, Pan Z, Shi W, Brown BS, Wymore RS, Cohen IS, Dixon JE, McKinnon D. KCNQ2 and KCNQ3 potassium channel subunits: molecular correlates of the M-channel. Science 1998;282:1890.

12 Lerche H, Biervert C, Alekov AK, Schleitoff L, Lindner M, Klingler W, Bretschneider F, Mitrovic N, Jurkat-Rott K, Lehmann-Horn F, Steinlein OK. A reduced $\mathrm{K}^{+}$current due to a novel mutation in KCNQ2 causes neonatal convulsions. Ann Neurol 1999;46:305-12.

13 Schwake M, Pusch M, Kharkovets T, Jentsch TJ. Surface expression and single channel properties of $\mathrm{KCN} 2 / \mathrm{KCNQ} 3, \mathrm{M}$-type $\mathrm{K}^{+}$channels involved in epilepsy. J Biol Chem 2000;275:13343-8.

14 Dedek K, Kunath B, Kananura C, Reuner U, Jentsch TJ, Steinlein OK. Myokymia and neonatal epilepsy caused by a mutation in the voltage sensor of the KCNQ2 K+ channel. Proc Natl Acad Sci U S A 2001;98:12272-7.

15 Wen $\mathrm{H}$, Levitan IB. Calmodulin is an auxiliary subunit of $K C N Q 2 / 3$ potassium channels. J Neurosci 2002;22:7991-8001.

16 Yus-Nájera E, Santana-Castro I, Villarroel A. The identification and characterization of noncontinuous calmodulin-binding site in noninactivating voltage-dependent $\mathrm{KCNQ}$ potassium channels. J Biol Chem 2002;277:28545-53.

17 Gamper N, Shapiro MS. Calmodulin mediates $\mathrm{Ca}^{2+}$-dependent modulation of M-type $\mathrm{K}^{+}$channels. J Gen Physiol 2003;122:17-31.

18 Wallace RH, Scheffer IE, Barnett S, Richards M, Dibbens L, Desai RR, LermanSagie T, Lev D, Mazarib A, Brand N, Ben-Zeev B, Goikman I, Singh R, Kremmidiotis G, Gardner A, Sutherland GR, George AL Jr, Mulley JC, Berkovic SF. Neuronal sodium-channel $\alpha 1$-subunit mutations in generalized epilepsy with febrile seizures plus. Am J Hum Genet 2001;68:859-65.

19 Tinel N, Lauritzen I, Chouabe C, Lazdunski M, Borsotto M. The KCNQ2 potassium channel: splice variants, functional and developmental expression. Brain localization and comparison with KCNQ3. FEBS Lett 1998:438:171-6.

20 Walhout AJM, Sordella R, Lu X, Hartley JL, Temple GF, Brasch MA, ThierryMieg N, Vidal M. Protein interaction mapping in $C$. elegans using proteins involved in vulval development. Science 2000;287:116-22.

21 Printen JA, Sprague GF Jr. Protein interactions in the yeast pheromone response pathway: Ste $5 p$ interacts with all members of the MAP kinase cascade. Genetics 1994;138:609-19

22 Moulard B, Picard F, le Hellard S, Agulhon C, Weiland S, Favre I, Bertrand S, Malafosse A, Bertrand D. lon channel variation causes epilepsies. Brain Res Brain Res Rev 2001;36:275-84.
23 Miraglia del Giudice E, Coppola G Scuccimarra G Cirillo G Bellini G Pascotto A. Benign familial neonatal convulsions (BFNC) resulting from mutation of the KCNQ2 voltage sensor. Eur J Hum Genet 2000;8:994-7.

24 Dedek K, Fusco L, Teloy N, Steinlein OK. Neonatal convulsions and epileptic encephalopathy in an Italian family with a missense mutation in the fifth transmembrane region of KCNQ2. Epilepsy Res 2003;54:21-7.

25 Lee WL, Biervert C, Hallmann K, Tay A, Dean JCS, Steinlein OK. A KCNQ2 splice site mutation causing benign neonatal convulsions in a Scottish family. Neuropediatrics 2000;31:9-12.

26 Biervert C, Steinlein OK. Structural and mutational analysis of KCNQ2, the major gene locus for benign familial neonatal convulsions. Hum Genet 1999; 104:234-40.

27 Coppola G, Castaldo P, Miraglia del Guidice E, Bellini G, Galasso F, Soldovieri MV, Anzalone L, Sferro C, Annunziato L, Pascotto A, Taglialatela M. A novel KCNQ2 $\mathrm{K}^{+}$channel mutation in benign neonatal convulsions with centrotemporal spikes. Neurology 2003;61:131-4

28 Rogawski MA. KCNQ2/KCNQ3 $\mathrm{K}^{+}$channels and the molecular pathogenesis of epilepsy: implications for therapy. Trends Neurosci 2000;23:393-8.

29 Castaldo P, Miraglia del Giudice E, Coppola G, Pascotto A, Annunziato L, Taglialatela M. Benign familial neonatal convulsions caused by altered gating of KCNQ2/KCNQ3 potassium channels. J Neurosci 2002;22:RC199.

30 Malievic S, Lerche C, Seebohm G, Alekov AK, Busch AE, Lerche H. C-terminal interaction of KCNQ2 and KCNQ3 $\mathrm{K}^{+}$channels. J Physiol 2003:548:353-60.

31 Schwake M, Jentsch TJ, Friedrich T. A carboxy-terminal domain determines the subunit specificity of $\mathrm{KCNQ} \mathrm{K}^{+}$channel assembly. EMBO Rep 2003:4:76-81.

32 Schmitt N, Schwarz M, Peretz A, Abitbol I, Attali B, Pongs O. A recessive C terminal Jervell and Lange-Nielsen mutation of the KCNQ1 channel impairs subunit assembly. EMBO J 2000;19:332-40.

33 Cooper EC, Aldape KD, Abosch A, Barbaro NM, Berger MS, Peacock WS, Jan YN, Jan LY. Colocalization and coassembly of two human brain M-type potassium channel subunits that are mutated in epilepsy. Proc Natl Acad Sci U S A 2000;97:4914-9.

34 Saimi Y, Kung C. Calmodulin as an ion channel subunit. Annu Rev Physiol 2002:64:289-311.

35 Cruzblanca $H$, Koh DS, Hille B. Bradykinin inhibits $M$ current via phospholipase $\mathrm{C}$ and $\mathrm{Ca}^{2+}$ release from $\mathrm{IP}_{3}$-sensitive $\mathrm{Ca}^{2+}$ stores in rat sympathetic neurons. Proc Natl Acad Sci U S A 1998;95:7151-6.

36 Filippov AK, Webb TE, Barnard EA, Brown DA. P2Y2 nucleotide receptors expressed heterologously in sympathetic neurons inhibit both $\mathrm{N}$-type $\mathrm{Ca}^{2+}$ and M-type $\mathrm{K}^{+}$currents. J Neurosci 1998;18:5170-9.

37 Bofill-Cardona E, Vartian N, Nanoff C, Freissmuth M, Boehm S. Two different signalling mechanisms involved in the excitation of rat sympathetic neurons by uridine nucleotides. Mol Pharmacol 2000:57:1 165-72.

38 Delmas $\mathbf{P}$, Wanaverbecq N, Abogadie FC, Mistry M, Brown DA. Signalling microdomains define the specificity of receptor-mediated $\mathrm{IP}_{3}$ pathways in neurons. Neuron 2002;34:209-20.

39 Scholze T, Moskvina E, Mayer M, Just H, Kubista H, Boehm S. Sympathoexcitation by bradykinin involves $\mathrm{Ca}^{2+}$-independent protein kinase C. J Neurosci 2002;22:5823-32. 